\title{
CURRENT TRENDS IN THE MANAGEMENT OF DIABETES MELLITUS: THE DENTIST'S PERSPECTIVE
}

\author{
${ }^{*}$ C.C. Azodo \\ Nigeria \\ Correspondence: \\ Dr C.C. Azodo \\ Department of Periodontics \\ University of Benin Teaching Hospital \\ P.M.B. 1111 Benin City \\ Edo State, Nigeria \\ Email: clementazodo@yahoo.com
}

*Department of Periodontics, University of Benin Teaching Hospital Benin City,

\section{ABSTRACT}

Diabetes mellitus (DM) is a chronic, non-communicable disease with concomitant oral manifestations that impact on dental care. Approximately $40-80$ persons in 2,000 adult population visiting dental practice are diabetic and about half are unaware of their condition. The average dentist attends to over 100 diabetic patients per year. It is important for dentists to be familiar with the medical management of patients with DM, and to recognize the signs and symptoms of undiagnosed or poorly controlled disease. Oral diseases and their treatments are known to affect glycemic control and insulin resistance in diabetic patient. By taking an active role in the diagnosis and treatment of oral conditions associated with DM, dentists also may contribute to the maintenance of optimum health in patients with this condition. Improved knowledge of this condition among dental practitioner will translate to enhanced management of oral diseases, prevention of complication and overall improvement in quality of life of diabetic patients. Emphasis should therefore be placed on the multidisciplinary and team approach in diabetes mellitus patient management.

\begin{abstract}
INTRODUCTION
Diabetes mellitus (DM) is a chronic, non-communicable disease and also one of the major global public health issues. It produces many complex changes in the lives of those affected. Diabetes mellitus is defined as a clinical syndrome characterized by hyperglycemia due to absolute or relative deficiency of insulin ${ }^{1}$.

Diabetes mellitus is an etiologically and clinically heterogeneous group of metabolic disorders that share the commonality of hyperglycemia. It is chronic disorder characterized by:

- Hyperglycemia

- Major abnormalities in carbohydrate, fat and protein metabolism.

- Marked propensity to develop relatively specific forms of vascular, renal, ocular, neurologic and periodontal complications

It is a common disease with concomitant oral manifestations that impact on dental care. Virtually every practicing dentist encounters patients with known or undiagnosed diabetes. General and oral signs and symptoms suggestive of uncontrolled or poorly controlled DM should be at every
\end{abstract}


dentist's finger tips. Laboratory or inter-office screening tests should be a part of dental practice.

\section{EPIDEMIOLOGY}

Prevalence of DM in the population African communities is on the increase due to lifestyle changes. The prevalence of DM in South Western Nigeria is $4.76 \%$ with $2.38 \%$ as undiagnosed $\mathrm{DM}^{2}$. Approximately 4080 persons in 2,000 adult population visiting dental practice are diabetic and about half of this group are unaware of their condition. The prevalence of undiagnosed DM in University of Benin Teaching Hospital dental clinic is $4.5 \%{ }^{3}$. The average dentist attends to over 100 diabetic patients per year.

\section{CLASSIFICATION OF DIABETES MELLITUS}

1. Primary (No associated disease present)

A. Insulin Dependent Diabetes Mellitus (IDDM)

- Immune mediated DM, Idiopathic

B. Non-insulin Dependent Diabetes Mellitus (NIDDM)

- Non- Autoimmune

2. Secondary (identifiable disease conditions present)

A. Pancreatic Disease

B. Endocrinopathies

C. Drug/Chemical usage

D. Insulin receptor abnormalities

E. Associated with genetic syndromes

F. Malnutrition

G. Complication of surgery

$\mathrm{H}$. Other causes like infections

\section{Gestational Diabetes mellitus}

This is defined as any degree of glucose intolerance with onset or first recognition during pregnancy 4 . Gestational diabetes complicates 2\% to $5 \%$ of all pregnancies. In the majority of cases, glucose regulation will return to normal after delivery.
However, women who have had gestational diabetes are at increased risk of developing NIDDM later in life ${ }^{5,6}$.

\section{MANAGEMENT}

History: it is important to always take a good history of the condition. Patient may complain of polyuria, polydipsia, polyphagia and weight loss. Patient may be asymptomatic thus may be an incidental finding. Patient may also present with complication like purititis vulvae or balanitis, mental apathy, confusion, retinopathy, neuropathy, angiopathy, nephropathy, Infections, periodontal disease, hyperlipidaemia and artherosclerosis.

Clinical examination: Detailed clinical examination may reveal loose dry skin, furred tongue, cracked lips, tachycardia, hypotension, decreased intraocular pressure, deep sighing breath of acidosis, fetid/sickly smell of acetone, coma (Diabetic ketoacidotic coma, Hypoglycemic, non ketotic hyperglycemic coma and lactic acidotic coma) depression or loss of tendon reflexes, impaired vibration sensation of distal aspect of leg, hypertension, impalpable pulses in feet, bruits over carotid and femoral arteries and gangrene of feet.

Investigation

A. Urine sugar testing

- Clinstix, clinitest tablet

- Urine ketone testing

- Nitroprusside test

B. Biochemical Investigations

- Fasting blood sugar

- Random blood sugar

C. Oral glucose tolerance test

D. Investigation to exclude complications:

- Fundoscopy

- E and U and creatinine

- Doppler flow meter.

\section{Treatment}

1. Diet alone 
2. Diet with oral hypoglycemic drugs

3. Diet with insulin

Diet: Diet could be

- Low energy weight reduction diet

- Weight maintenance diet

Points to note in diet

- Carbohydrate should be taken in form of starch and complex sugars

- $\quad$ sucrose and glucose should be avoided

- Diet should include more fibre rich foods like beans and legumes

- Protein should be consumed as it promotes satiety and adherence to carbohydrate allowance

- Total fat should be reduced with increase in unsaturated fat

- Other forms of cooking like grilling, baking, poaching, steaming are preferred to frying

- Fish is favoured as it is rich in long chain unsaturated fatty acid

- Abstinence from alcohol should be encouraged

- Salt intake should be reduced

- Non-nutritive sweetner like saccharin and aspartame are acceptable and nutritive type like sorbitol and fructose should be taken in controlled quantity

Drugs

1. Oral hypoglycemic drugs

A Sulphonurea like Tolbutamide, Chlorpropamide (Diabinese)

Second generation drugs like Glipizide (Glucotrol), Gliclazide, Glibenclamide Glyburide (DiaBeta, Micronase), Glimepiride (Amaryl)

B Meglitinides

Repaglinide (Prandin)

C Biguanides
Metformin (Glucophage)

D a-Glucosidaselnhibitors

Acarbose (Precose)

Miglitol (Glyset)

E Thiazolidinediones

Rosiglitazone maleate (Avandia)

Pioglitazone (Actos)

2. Insulin: could be classified:

A. Rapid acting, Short acting, Intermediate acting or Long acting

B. Porcine, Bovine and human types

Monitoring

1 Self monitoring/Bedside monitoring of blood using glucometers

2 Glycated proteins

- Haemoglobin

- Albumin:

- Total; serum protein (fructosamine)

3. Ketone bodies: Acetone, Acetoacetate and $B$ hydroxybutyric acid

4. Proteins

5. Albumin

\section{ORAL MANIFESTATIONS AND} COMPLICATIONS

$\square$ Periodontal disease

$\square$ Dental caries

$\square$ Salivary gland dysfunction like xerostomia

- Fungal infections

$\square$ Lichen planus and lichenoid reaction $^{7}$

- Infections like osteomyelitis

$\square$ Delayed healing

alteration of taste or taste impairment

Burning mouth sensation

Neurosensory dysaesthesias

Premature tooth loss

$\square$ Others

\section{PERIODONTAL DISEASE}

Periodontal disease is now considered the sixth complication of DM both in IDDM and NIDDM $^{8}$. Children with IDDM are more prone to calculus accumulation $^{9}$. DM children are at a 
significantly higher risk for gingival bleeding. An increase in gingival bleeding, associated with hyperglycaemia, suggests hyperglycaemia-associated biological alterations, which lower host resistance toward plaque ${ }^{10}$. DMrelated oral complications affect the primary periodontium as early as age $6^{11}$. Other periodontal features are Bleeding on probing and high plaque index and increased clinical attachment loss ${ }^{12,13}$. Young adults and adolescent diabetics have a greater prevalence of gingival inflammatory hypertrophy and periodontal disease than their non-diabetic counterpart. The clinical manifestations of periodontal disease in adults and young diabetics are more severe than those observed in the non-diabetic population. Poorly controlled diabetics respond differently to bacterial plaque at the gum line than well-controlled diabetics and non-diabetics. This is probably due to elevated serum triglycerides. Decreased metabolic control in type 2 diabetics results in increased serum triglycerides and has a negative influence on all clinical measures of periodontal health, particularly in patients without preexisting periodontitis ${ }^{14}$. Increased serum triglyceride level in uncontrolled diabetics seems to be related greater attachment loss and probing depths. Poorly controlled diabetics have more cytokines in their gingival tissue, causing destructive inflammation of the gums ${ }^{14}$. In turn, beneficial proteins (growth factors) are reduced, interfering with the healing response to infection $^{14}$.

DM patients have a greater prevalence and extent of periodontal pockets ${ }^{15}$. DM patients react with an abnormally high degree of inflammation to an equivalent bacterial burden ${ }^{16}$. Poorlycontrolled diabetics, with extensive calculus deposition, had more periodontitis and tooth loss than wellcontrolled diabetics or non-diabetics. Long-duration diabetics were also at greater risk of periodontitis ${ }^{15}$. Diabetics who maintained reasonably good metabolic control exhibited more periodontal pockets than nondiabetics $^{15}$.

The increased prevalence of gingival and periodontal disease in diabetics is assumed to be multifactorial in origin. Deposition of advanced glycosylated end products (AGE) in gingival capillary walls as well as in the collagen of the periodontal ligament and the alveolar bone matrix, increased levels of low density lipoprotein with atheroma formation, hyperglycemia interfering with normal periodontal wound healing, altered immune response, increased oxidation, altered polymorphonuclear leukocyte functions and genetics are all contributing factors to the development of periodontal disease in the diabetics

\section{Mechanism of Periodontal diseases} in DM

1. Microangiopathy altering antigenic challenge.

2. Altered subgingival flora/change in components of gingival crevicular fluid

3. Increased collagen breakdown.

4. Altered cell-mediated immune response and impaired neutrophil chemotaxis.

5. Dysregulation of the normal cytokine/growth factor signaling axis seen in poorly controlled type 2 diabetics ${ }^{14}$.

In conclusion, mechanisms by which diabetes may contribute to periodontitis include vascular changes, neutrophil dysfunction, altered collagen synthesis, and genetic predisposition $^{15}$.

\section{DENTAL CARIES}

Increased dental caries prevalence in adult with diabetes mellitus is due to 
xerostomia and increase in saliva glucose. Hyperglycemic state has shown a positive association with dental caries. Adult patients with poor control seem to have more coronal caries.

Patients with IDDM have higher number of filled teeth than non-NIDDM while NIDDM have significantly higher number of extracted teeth ${ }^{17}$.

Diabetic patients have been said to be more caries prone than the general population $^{18}$. But in a study ${ }^{19}$, only long duration diabetics exhibited more decayed proximal tooth surfaces than non-diabetics.

Women with long diabetes duration, however, exhibited more endodontically treated teeth with periapical lesions than women with short diabetes duration and women without diabetes ${ }^{19}$.

Long duration diabetics exhibited teeth with periapical lesions to a greater extent than the other groups ${ }^{19}$.

\section{SALIVARY GLAND DYSFUNCTION:}

A. Xerostomia is common, $82 \%$ prevalence has been documented $^{20}$. Xerostomia is associated with burning mouth symptoms ${ }^{21}$. It also increases risk for candidal infection.

B. Salivary buffering capacities, salivary $\mathrm{pH}$ and peroxidase activity is lowered ${ }^{22}$.

C. Sialosis has also been documented as a possible oral manifestation of $\mathrm{DM}^{23-25}$.

D. Sialorrhoea is seen in a few cases and is usually due neuropathy ${ }^{24}$.

Mechanism of xerostomia

- Polyuria is an indirect cause of xerostomia

- Substituting parenchyma of major salivary gland functioning tissue with adipose tissue reduces quantitative and qualitative saliva production
- Saliva secretion is more reduced by xerogenic drugs and autonomic nervous dysfunction in patients with non-insulin-dependent diabetes ${ }^{26}$.

\section{LICHEN \\ PLANUS/LICHENOID \\ REACTION:}

The prevalence of oral lichen planus is $5.76 \%$ and $2.83 \%$ in IDDM and NIDDM respectively ${ }^{27}$. Gibson et al. also associated the finding of oral lichen planus to diabetes ${ }^{28}$. Erosive or ulcerative type of lichen planus/ lichenoid reaction mainly occurs in $\mathrm{DM}^{7,29}$ and the most favoured site for lichen planus in DM is the tongue. Chlopropamide (sulphonylurea) has also been said to cause lichenoid reaction ${ }^{30}$.

\section{FUNGAL INFECTIONS}

Candidasis (erythematous or pseudomembranous) is the commonest fungal infection in DM and the manifestations include: thrush, median rhomboid glossitis, denture stomatitis, and angular cheilitis. A study reported that more subjects with IDDM than control subjects without IDDM were found to have clinical manifestations of candidiasis, including median rhomboid glossitis, denture stomatitis, and angular cheilitis ${ }^{31}$. Subject with IDDM have the likelihood of having Candida pseudohyphae in their cytologic smears, and Candida pseudohyphae is significantly associated poor glycemic control ${ }^{31}$.

\section{A. Denture stomatitis}

The adherence of Candida albicans to palatal epithelial cells of patients with NIDDM predisposes to Candidaassociated denture stomatitis ${ }^{32}$. Candida albicans are more frequently isolated in denture wearing patients with $\mathrm{DM}^{33}$. Glycosylated haemoglobin greater than $12 \%$ remained highly predictive of oral yeast infection, especially among diabetics without dentures ${ }^{34}$.

\section{Mechanism of Candidasis}


- Hyposalivation

- High glucose concentrations in blood and body fluids promote the overgrowth of certain fungal pathogens, particularly the Candida species.

- Increase in salivary glucose promotes greater adherence of fungi to epithelia

- Increase glucose levels interfere with the defense mechanism of neutrophils, altered function facilitating possible candidosis ${ }^{35}$.

- The PMN leukocytes from diabetic patients, especially those with candidosis, produced less free oxygen radicals and exhibited reduced phagocytosis and intracellular killing of Candida cells associated with this reduced $\mathrm{O}_{2}-$ generation during the infection ${ }^{36}$.

- Damage of the microvascularization, leading to decreased blood supply can predispose to infections like candidosis, due to a reduction of the local resistance of the tissues.

B. Mucormycosis (phycomycosi, zygomycosis)

It is an acute opportunistic infection caused by a saprophytic fungus found in soil, bread molds, and decaying fruits and vegetables. Poorly controlled diabetics is a predisposing factor for mucormycosis but a case has however been reported in the maxilla of a patient with wellcontrolled diabetes ${ }^{37}$.

\section{NEUROSENSORY DYSESTHESIAS}

Diabetic patients may experience longlasting oral dysaesthesias, which could adversely affect oral hygiene maintenance. Peripheral neuropathies can impair the use of oral hygiene devices, and diabetic retinopathy can produce visual disturbances, ultimately leading to blindness, which, in turn, also could impair daily oral and prosthesis hygiene. Dysphagia, another sequelae of diabetes, is caused by altered strength, speed and/or coordination of the cranial nerve musculature ${ }^{38}$.

\section{BURNING MOUTH SYNDROME (BMS):}

Burning mouth syndrome has been attributed secondarily to DM, poor glycemic control, and diabetic neuropathy.BMS or related discomforts occurred slightly more frequently in IDDM population especially female with peripheral neuropathy. Similarities between BMS and DM peripheral neuropathy suggest that a neuropathic process may be an underlying source of BMS in some patients who have no apparent oral abnormality ${ }^{39}$.

\section{PREMALIGNANT ORAL LESIONS}

An association between DM and premalignant oral lesions has been observed among women in India but the underlying mechanisms are not clear $^{40}$.

\section{BONE DENSITY}

Bone mineral density of the mandible does not seem to be affected in patients with NIDDM $^{41}$. Lower bone mineral density seen in IDDM is probably due to more rapid bone loss after the onset of the DM ${ }^{42}$.

\section{TASTE SENSATION IMPAIRMENT}

Newly-diagnosed NIDDM patients have a blunted taste response, which displays a degree of specificity to glucose. This is partially reversed after correction of hyperglycemia, and is independent of somatic or autonomic nerve function. This taste abnormality may influence the premorbid choice of nutrients, with a preference for sweettasting foods, thereby exacerbating hyperglycemia $^{43}$. Taste sensation abnormalities could be due to xerostomia or disordered glucose receptors ${ }^{44}$. Taste may diminish and 
influence food choices in favor of sweet tasting foods with highly refined carbohydrate content that may worsen a diabetic's dental and overall health. In a study, more than one-third of adults with diabetes had hypogeusia or diminished taste perception, which could result in hyperphagia and obesity $^{45}$. This sensory dysfunction can inhibit the ability to maintain a proper diet and can lead poor glycemic control.

\section{TOOTH ERUPTION}

Children with diabetes exhibit accelerated tooth eruption ${ }^{46}$.

INCREASED RISK OF INFECTION

$\mathrm{DM}$ is a predisposing condition for odontogenic infections. There is increased prevalence of periodontal abscess, dry socket and osteomyelitis. Recurrent periodontal abscesses are typical of diabetic patients. DMcomplicated infections are severe because of neutrophil suppression. Blood sugar level estimation is essential for patients with oral infections.

Mechanism of increased risk of infection

This is still unclear, but

- Macrophage metabolism alteration occurs, with inhibition of phagocytosis.

- Immunological defect and deficient leucocytes functions. Functions of immune cells, including neutrophil, monocytes and macrophages are altered.

- All steps of PMN functioning which include PMN chemotaxis, spontaneous activation of PMN cells, increased free radical production; after stimulation are altered in diabetic patients, which may increase the risk of vascular complications and infectious episodes ${ }^{47}$. Neutrophil adherence, chemotaxis and phagocytosis are also impaired thus inhibiting bacteria killing.

- Decrease production of antibodies

- Peripheral neuropathy and poor peripheral circulation

\section{DELAYED HEALING OF WOUNDS}

Diabetes also impairs the healing process in the oral cavity and periodontal abscesses can develop. This is why regular dental checkups and periodontal examinations are so important.

Wound healing appears to be compromised in diabetics,

Mechanism of delayed wound healing

- Microangiopathy and utilization of protein for energy may retard the repair of tissues.

- Primary reparative cell in periodontium, the fibroblast, does not function properly in high glucose environments ${ }^{48}$.

- There is altered cellular activities and failure of PMNs to migrate toward the area of wound healing.

- Collagen synthesis is decreased in diabetics. Decreased crosslinking and glycosylation of collagen renders collagen produced in DM more soluble and possibly with a decrease remodeling time.

- Increased collagenase production may degrade newly formed collagen.

- Collagen produced by fibroblast is susceptible to rapid degradation by matrix metalloproteinase enzymes which is elevated in $\mathrm{DM}^{49}$.

PREMATURE TOOTH LOSS 
IDDM patients showed a significantly lower number of teeth present. DM is a certified cause of premature tooth loss.

\section{OTHERS}

A. TRAUMATIC ULCERS AND IRRITATION FIBROMAS

Type 1 DM patients have a higher prevalence of oral traumatic ulcers and irritation fibromas than do nondiabetic control subjects ${ }^{50}$. These findings may be related to altered wound healing patterns in these patients.

B. Halitosis can be perceived in diabetic patients due periodontal diseases. Acetone breath odour is perceived in cases of diabetic ketoacidosis.

C. Pulpitis: mechanism is due to degeneration of vasculature.

D. Neuropathies : may affect cranial nerves like facial nerve

E. Bells palsy

F. Ulcers like recurrent aphthous stomatitis $^{51}$.

G. Leukoplakia--correlating atrophy of oral mucosa to hyposalivation and deficient hygiene ${ }^{30}$.

H. DM decreases endodontic treatment success in cases with preoperative periradicular lesions

I. Increased flare-ups during endodontic treatment in those receiving insulin have increased pre-operative periradicular pain

\section{ROLE OF DENTISTS IN DM CARE}

1. Screening, early diagnosis and referral

2. Health education and dietary advice

3. Routine dental treatment to DM patients

4. Treatment of oral lesions of DM patients

5. Emergency care

6. Help in formation of support groups
7. Role in team approach

8. Role in research

\section{SCREENING, EARLY \\ DIAGNOSIS AND REFERRAL}

Dentists can be among the first to urge patients to get tested for the chronic disease. As a dentist may be the first healthcare professional to suspect a patient has diabetes, order appropriate tests or refer patients to physicians to be tested. The dental practitioner should be aware of the oral manifestations of DM in order to spot initial symptoms of the disease. Dental healthcare providers are involved in screening for this disease, as well as treating numerous patients with $\mathrm{DM}^{52}$.

\section{HEALTH EDUCATION AND DIETARY ADVICE}

Dentists are known to maintain a long term contact with their patient. This will obviously serve as an avenue for education and reminder to DM patient about their health, nutrition and exercise. Routine assessment of BMI done in dental clinic will prompt advice and referral to the nutritionist. The 6 monthly prophylaxes is an opportunity for reiterating health advice

\section{ROUTINE DENTAL TREATMENT TO DM PATIENTS}

Dental providers must be aware of the rapid changes concerning management of individuals with DM and must understand the significant impact DM has on dental treatment.

Precautions in DM oral Care:

- To provide competent care to patients with diabetes mellitus, dental clinicians must understand the disease, its treatment, and the impact the disease and its treatment may have on the patient's ability to undergo and respond to dental care. 
- To minimize the risk of an intraoperative emergency, clinicians need to consider some issues before initiating dental treatment.

- Medical history is very important. Patient's glycemic control should be ascertained at the glycemic control at initial appointment.

- Ascertain glucose levels, frequency of hypoglycemic episodes, medication, dosage and timing.

Dental management considerations (See Table I for some information)

- Defer surgery until diabetes is well controlled by physician

- Scheduling of visits: In general, early morning appointments are advisable since endogenous cortisol levels are generally higher at this time (cortisol increases blood sugar levels). For patients receiving insulin therapy, appointments should be scheduled so that they do not coincide with peaks of insulin activity, since that is the period of maximal risk of developing hypoglycemia ${ }^{6}$.

- Avoid lengthy appointment.

- If a lengthy, especially surgical procedure is to be undertaken, the patient's physician should be consulted.

- Patient should take normal breakfast and drugs or insulin before treatment. Ensure that the patient has eaten normally and taken medications as usual.

- Emotional and physical stress increases the amount of secreted cortisol and epinephrine which induce hyperglycemia. Therefore, if the patient is very apprehensive pre-treatment sedation should be contemplated.
- Blood glucose monitoring is also very important blood glucose level should be noted before beginning a dental procedure. Use anxiety reduction protocol

- Monitor pulse, respiration and blood pressure both during and after surgery. Maintain verbal contact with patient during surgery

- Watch for signs of hypoglycemia

- Give prophylactic antibiotics, especially in pre-operation contamination wound.

- In cases of established infection-Treat infections aggressively as chronic oral infection itself may contribute to raised blood glucose levels and hence to the later complications of diabetes. Acute infection in the oral cavity needs specific and aggressive management, just as in the acutely infected diabetic foot ${ }^{53}$.

Dental surgery under General Anaesthesia (G. A)

$\square$ Admit into hospital under a physician.

$\square$ Long acting insulin should be changed to soluble form

- Operate first in the morning

- Give Normal saline infusion

$\square$ Do blood sugar estimation before insulin and glucose infusion

$\square$ Control infection at site of operation by careful oral prophylaxis

$\square$ Take special care to avoid postoperative infection

- Minimize trauma

$\square$ Use of antibiotics postoperatively

\section{TREATMENTS OF ORAL LESION OF DM \\ Periodontal disease}


Minimizing plaque and calculus in the oral cavity, through careful self-care and regular professional care, is important to reduce the risk of periodontitis in diabetics ${ }^{54}$. The emphasis on oral hygiene is valuable in preventing future periodontal complications in DM patients. Professional oral prophylaxes, oral hygiene instruction and improved insulin therapy results in reduced insulin resistance.

If periodontitis is already present, blood sugar control by endocrinologist, professional oral prophylaxis chlorhexidine mouth wash and periodontal surgery are adequate.

New evidence suggests that advanced periodontal disease may interfere with DM control and the physician should be made aware of the patient's periodontal status.

A well-controlled diabetes mellitus patient can receive safe and effective periodontal therapy

Periodontal health can be achieved in DM patient with:

- Proper and timely periodontal therapy

Patient's effective oral hygiene measures

Appropriate

supportive

periodontal recall therapy.

Periodontal destruction can start very early in life in DM and becomes more prominent as children become adolescents. Programs designed to promote periodontal disease prevention and treatment should be provided to young patients with $\mathrm{DM}^{55}$.

The standards of care for children with diabetes should include screening and referral programs aimed at oral health promotion and disease prevention.
Importance of Periodontal treatment

$\square$ Treating gum disease in diabetic patients can help them keep their diabetes under control. Evidence of this was noted by Ciancio et al 2004.

口 Periodontal therapy in uncontrolled DM reduces the required insulin dose.

$\square$ Glycemic control is easily achieved after periodontal treatment. Improved $\mathrm{HbA} 1 \mathrm{C}$ occurs after periodontal therapy

\section{Dental caries}

Restore carious tooth and give preventive instructions.

Salivary gland dysfunction and oral burning

$>$ Maintenance of adequate oral hydration (water, ice chips, saliva substitutes, sugarless gum)

$>$ Restriction of caffeine and alcohol intake

$>$ Saliva is important in the maintenance and the preservation of oral health, management of oral diseases in diabetic patients should include a comprehensive evaluation of salivary function ${ }^{56}$.

\section{Candida infection}

Antifungal and proper denture hygiene if implicated

$>$ removing and cleaning dentures daily

$>$ Good diabetic control

$>$ smoking cessation

$>$ Recent reports have indicated that clonazepam may be beneficial in some patients with complaints of oral burning sensation $^{57}$.

\section{Lichen Planus and Lichenoid Reactions}

The erosive type is very painful thus a topical anaesthetic may help 
to reduce and relieve some of this condition.

Orthodontic treatment: Fixed appliance orthodontic treatment are now done for well motivated and well controlled DM patients after counseling on proper oral hygiene.

Dental implant: Because the life expectancy of individuals continues to increase, dentists providing dental implant treatment can expect to see an increasing number of patients with diabetes mellitus. DM is no longer considered to be a contraindication for implant-supported prostheses, provided that the patient's blood sugar is under control, and patient is highly motivated for oral hygiene procedures ${ }^{58}$. Implant failure is recorded more in type2 diabetic patients than non-diabetic patients ${ }^{59}$.

Presently, diabetic patients are being treated successfully for all types of edentulism, including bone-grafting treatment. Screening for diabetes and trying to ensure that implant candidates are in metabolic control are recommended to increase the chances of successful osseointegration ${ }^{60}$.

The clinical outcome of dental implants in a selected group of patients with well-controlled type 2 diabetes mellitus is satisfying and encouraging ${ }^{61}$. Implant success rate in DM is between $94.3-97.3 \%{ }^{60,62}$.

\section{Endodontic care}

Patients with diabetes have a reduced likelihood of success of endodontic treatment in cases with preoperative periradicular lesions. Patients with diabetes, who are treated endodontically, should be assessed carefully and be treated with effective antimicrobial root canal regimens, particularly in cases with preoperative lesions ${ }^{63}$.

\section{EMERGENCY DENTAL CARE OF DIABETIC PATIENTS}

Undiagnosed or uncontrolled DM patient should receive only emergency care until their health status has been properly evaluated.

Antibiotic therapy should be administered in conjunction with any necessary surgical procedure. Dentist must be prepared to manage diabetic emergencies should they occur in the dental office, and hypoglycemic incidents are most likely.

\section{A. Hypoglycemia:}

Initial signs: mood changes, decreased spontaneity, hunger and weakness followed by sweating, incoherence, palpitations, tachycardia leading to unconsciousness, hypotension, hypothermia, seizures, coma, even death.

Treatment requires intake of calories with quickly absorbed sources of glucose; 15 grams of fast-acting oral carbohydrate (tablets, juice, or candy) if the patient is able to chew/swallow. If the diabetic patient becomes unconscious or swallowing ability is compromised, then glucagon $1 \mathrm{mg}$ should be administered intramuscularly as well as intravenous glucose i.e $25-30 \mathrm{ml} 50 \%$ dextrose solution intravenously over $3 \mathrm{~min}$ period.

B. SEVERE HYPERGLYCEMIA:

This usually has a prolonged onset. Ketoacidosis may develop with nausea, vomiting, abdominal pain and acetone odor. It is difficult to differentiate between hypoglycemia or hyperglycemia. Hyperglycemia need medication intervention and insulin administration. In emergency situation, glucose should be given first. A small amount is unlikely to cause significant harm.

\section{ROLE IN TEAM APPROACH}

The management of diabetes and its complication involves many specialist like endocrinologist, nephrologist, neurologist, ophthalmology, orthopedic surgeon, pediatrician and nutrititionist. The role of a periodontist and a paedodontics is preventive as patients 
with better periodontal health achieve better glycemic control with insulin and oral hypoglycemic drugs. Collaboration between the endocrinologist and Periodontist is important, as treatment of periodontitis in DM reduces the quantity of insulin needed to achieve glycemic control. Early treatment of oral infections like periodontal abscess, is an effective way of preventing insulin resistance and complications like hyperglycemic coma

\section{HELP IN FORMATION OF SUPPORT GROUPS}

DM is a chronic illness without any age limit. Support group is particularly important for parents of children with DM and older people with Diabetes. A dentist can play an important role in support groups where experiences are shared and knowledge about the condition is improved. This will lead to improved quality of life.

\section{ROLE IN HEALTH EDUCATION}

In Nigeria, majority of DM patients do not know that DM can contribute to oral ill health and quite a number of DM patients $(53.9 \%$ and $46.8 \%)$ are not aware of the need for glycemic control to prevent and control oral infections in diabetics ${ }^{64}$ the need for oral health education.

\section{CONCLUSION}

To provide competent care to patients with diabetes mellitus, dental clinicians must understand the disease, its treatment, and the impact the disease and its treatment may have on the patient's ability to undergo and respond to dental care. Safely managing the patient with DM requires effective communication among multiple health care providers. The dental team may contribute greatly to the shared care of DM with the diabetic team itself, and regular liaison is strongly recommended. The information presented in this seminar report should help dentists to deliver optimum treatment to patients with DM.

\section{Table I: BASIC PATIENT MANAGEMENT STRATEGIES ${ }^{64}$}

*Schedule dental appointments in the early to mid-morning hours

* Keep appointments short

* Use adjunct sedation procedures when appropriate

* Instruct patient to continue normal dietary intake before dental procedures

* Prior to an invasive procedure, check the patient's blood glucose

* Modify diet to soft solids and liquids when patient is expected to have difficulty eating solid foods after dental procedures

* Perform appropriate follow-up care in the postoperative period

* Frequent recall examinations and prophylaxis

* Use of topical fluoride when patients are at risk of caries

* Supportive, palliative care for dry mouth, using salivary substitutes

\section{REFERENCES}

1. Edwards CRW, Baird JD, Toft AD, Frier BM, Shepherd J.
Endocrine and metabolic diseases In Edwards CRW, Bouchier IAD, Haslett C, 


Chilvers ER.Davidson's
principles and practice of
medicine $17^{\text {th }}$ eds church
Livinstone, London, Britian
1996: $669-774$

2. Oyegbade OO, Abioye-Kuteyi EA, Kolawole BA, Ezeoma IT, Bello IS. Screening for diabetes mellitus in a Nigerian family practice population. SA Fam Pract 2007; 49(8):15

3. Ojehanon PI, Akhionbare $\mathrm{O}$. Prevalence of undiagnosed diabetes pellitus among dental patients in Edo State, Nigeria. Journal of Medicine and Biomedical Research. 2006; 5(1):24-28.

4. Metzger BE, Coustan DR (Eds.): Proceedings of the Fourth International WorkshopConference on Gestational Diabetes Mellitus. Diabetes Care1998; 21 (Suppl. 2):B1B167.

5. Therapy for Diabetes Mellitus and Related Disorders 3rd Edition. American Diabetes Association, 1998: 20-26.

6. Lalla RV, D'Ambrosio JA. Dental management considerations for the patient with diabetes mellitus. J Am Dent Assoc. 2001; 132(10): 1425-1432.

7. Brown RS, Bottomley WK, Puent E, Lavigne GJ: A retrospective evaluation of 193 patients with oral lichen planus. J Oral Pathol Med 1993; 22: 6972.

8. Loe H. Periodontal disease: the sixth complication of diabetes mellitus. Diabetes Care 1993; 16:329-34.

9. Siudikiene J, Maciulskiene V, Dobrovolskiene $R$, Nedzelskiene I. Oral hygiene in children with type I diabetes mellitus. Stomatologija. 2005; $7(1): 24-7$.

10. Karjalainen KM, Knuuttila ML.The onset of diabetes and poor metabolic control increases gingival bleeding in children and adolescents with insulin-dependent diabetes mellitus. J Clin Periodontol. 1996; 23(12):1060-7.

11. Lal S, Cheng B, Kaplan S, Softness B, Greenberg E, Goland RS, Lalla E, Lamster IB. Gingival bleeding in 6- to 13year-old children with diabetes mellitus. Pediatr Dent. 2007; 29(5):426-30.

12. Firatli E, Yilmaz O, Onan U. The relationship between clinical attachment loss and the duration of insulin-dependent diabetes mellitus (IDDM) in children and adolescents. J Clin Periodontol. 1996; 23(4):362366.

13. Firatli E. The relationship between clinical periodontal status and insulin-dependent diabetes mellitus. Results after 5 years. J Periodontol. 1997; 68(2):136-40.

14. Cutler CW, Machen RL, Jotwani R, lacopino AM. Heightened gingival inflammation and attachment loss in type 2 diabetics with hyperlipidemia. J Periodontol. 1999; 70(11):131321. 
15. Oliver RC, Tervonen T. Periodontitis and tooth loss: comparing diabetics with the general population. J Am Dent Assoc. 1993; 124(12):71-76.

16. Salvi GE, Beck JD, Offenbacher S. PGE2, IL-1 beta, and TNFalpha responses in diabetics as modifiers of periodontal disease expression. Ann Periodontol. 1998; 3(1):40-50.

17. Bacić M, Ciglar I, Granić M, Plancak D, Sutalo J. Dental status in a group of adult diabetic patients. Community Dent Oral Epidemiol. 1989; 17(6):313-6.

18. Jones RB, McCallum RM, Kay EJ, Kirkin V, McDonald P. Oral health and oral health behaviour in a population of diabetic outpatient clinic attenders. Community Dent Oral Epidemiol. 1992; 20(4):204-7.

19. Falk $H$, Hugoson $A$, Thorstensson $H$. Number of teeth, prevalence of caries and periapical lesions in insulindependent diabetics. Scand J Dent Res. 1989; 97(3):198-206.

20. Sreebny LM, Yu A, Green A, Valdini A. Xerostomia in diabetes mellitus. Diabetes Care. 1992; 15(7):900-4.

21.Zachariasen R: Diabetes mellitus and xerostomia. Compendium, XIII: 314-324, 1992.

22. Aren G, Sepet E, Ozdemir D, Dinççağ N, Güvener B, Firatli E. Periodontal health, salivary status, and metabolic control in children with type 1 diabetes mellitus. J Periodontol. 2003; 74(12):1789-95.

23. Russoto SB: A symptomatic parotid gland enlargement in diabetes mellitus. Oral Surg Oral Med Oral Pathol 52: 594598, 1981

24. Gibson J, Lamey PJ, Lewis M, Frier B. Oral manifestations of previously undiagnosed noninsulin dependent diabetes mellitus. J Oral Pathol Med. 1990; 19(6):284-7.

25. Quirino MRS, Birman EG, Paula CR.Oral Manifestations of Diabetes Mellitus in Controlled and Uncontrolled Patients. Braz Dent J 1995; 6(2): 131-136.

26. Meurman $\mathrm{JH}, \quad$ Collin $\mathrm{HL}$, Niskanen L, Töyry J, Alakuijala $P$, Keinänen $S$, Uusitupa $M$. Saliva in non-insulin-dependent diabetic patients and control subjects: The role of the autonomic nervous system. Oral Surg Oral Med Oral Pathol Oral Radiol Endod. 1998; 86(1):69-76.

27. Petrou-Amerikanou C, Markopoulos AK, Belazi M, Karamitsos D, Papanayotou P. Prevalence of oral lichen planus in diabetes mellitus according to the type of diabetes. Oral Dis. 1998; 4(1):37-40.

28. Gibson J, Lamey PJ, Lewis M, Frier B: Oral manifestations of previously undiagnosed noninsulin dependent diabetes mellitus. J Oral Pathol Med. 1990; 19: 284-287. 
29. Bagan JV, Donat JS, Penarrocha M, Milian MA, Sanchis JM. Oral lichen planus and diabetes mellitus. A clinicopathological study. Bull Group Int Rech Sci Stomatol Odontol. 1993; 36(1-2):3-6.

30. Albrecht M, Ba'no' czy J, Dinya E, Tama's G. Occurrence of oral leukoplakia and lichen planus in diabetes mellitus. J Oral Pathol Med 1992; 21:364,

31. Guggenheimer J, Moore PA, Rossie K, et al. Insulindependent diabetes mellitus and oral soft tissue pathologies, I: prevalence and characteristics of non-candidal lesions. Oral Surg Oral Med Oral Pathol Oral Radiol Endod 2000; 89:563-9

32. Dorocka-Bobkowska B, BudtzJörgensen E, Włoch S. Noninsulin-dependent diabetes mellitus as a risk factor for denture stomatitis. J Oral Pathol Med. 1996; 25(8):411-415.

33. Daniluk T, Tokajuk G, Stokowska W, Fiedoruk K, Ściepuk M, Zaremba ML, Rożkiewicz D, Cylwik-Rokicka D, Kędra BA, Anielska I, Górska $M$, Kędra BR. Occurrence rate of oral Candida albicans in denture wearer patients

34. Hill LV, Tan MH, Pereira LH, Embil. JA Association of oral candidiasis with diabetic control. Journal of Clinical Pathology 1989; 42:502-505.

35. Darwazeh AMG, MacFarlane TW, McCuish A, Lamey PJ: Mixed salivary glucose levels and candidal carriage in patients with diabetes mellitus. J Oral Pathol Med 1991; 20: 280-283.

36. Ueta E, Osaki T, Yoneda K, Yamamoto $T$. Prevalence of diabetes mellitus in odontogenic infections and oral candidiasis: an analysis of neutrophil suppression. J Oral Pathol Med. 1993; 22(4):168-74.

37. Jones $A C$, Bentsen TY, Freedman PD. Mucormycosis of the oral cavity. Oral Surg Oral Med Oral Pathol. 1993; 75(4):455-60.

38. Ship JA. Diabetes and oral health: An overview. J Am Dent Assoc. 2003; 134;4-10

39. Moore PA, Guggenheimer J, Orchard T. Burning mouth syndrome and peripheral neuropathy in patients with type 1 diabetes mellitus. J Diabetes Complications. 2007; 21(6):397402.

40. Dikshit RP, Ramadas K, Hashibe M, Thomas G, Somanathan $T$, Sankaranarayanan R. Association between diabetes mellitus and pre-malignant oral diseases : a cross sectional study in Kerala, India.

41. Ay S, Gursoy UK, Erselcan T, Marakoglu I. Assessment of mandibular bone mineral density in patients with type 2 diabetes mellitus. Dentomaxillofacial Radiology 2005; 34:327-331.

42. Tuominen JT, Impivaara $\mathrm{O}$, Puukka $P$, Rönnemaa T. Bone mineral density in patients with 
type 1 and type 2 diabetes. Diabetes Care 1999; 22:11961200 ,

43. Perros $P$, MacFarlane TW, Counsell C, Frier BM. Altered taste sensation in newlydiagnosed NIDDM. Diabetes Care 1996; 19(7): 768-770.

44. Rees TD. The diabetic dental patient. Dent Clin North Am 1994; 38:447-63.

45. Stolbova K, Hahn A, Benes B, Andel M, Treslova $L$. Gustometry of diabetes mellitus patients and obese patients. Int Tinnitus J 1999; 5(2):135-40.

46. Lal S, Cheng B, Kaplan S, Softness B, Greenberg E, Goland RS, Lalla E, Lamster IB. Accelerated tooth eruption in children with diabetes mellitus. Pediatrics. 2008; 121(5):e113943.

47. Delamaire $M$, Maugendre $D$, Moreno M, Le Goff MC, Allannic $\mathrm{H}$, Genetet B. Impaired leucocyte functions in diabetic patients. Diabet Med. 1997; 14(1):29-34.

48. Willershauschen-Zonchen B, Lemmen C, Hamm G. Influence of high glucose concentrations on glycosaminoglycan and collagen synthesis in cultured human gingival fibroblasts. J Clin Periodontol 1991; 18(3):190-5.

49. Golub LM, Lee HM, Ryan ME. Tetracyclines inhibit connective tissue breakdown by multiple non-antimicrobial mechanisms. Adv Dent Res 1998; 12(2):1226.
50. Guggenheimer J, Moore PA, Rossie K, Myers D, Mongelluzzo MB, Block HM, Weyant $\mathrm{R}$, Orchard $\mathrm{T}$. Insulindependent diabetes mellitus and oral soft tissue pathologies: II. Prevalence and characteristics of Candida and Candidal lesions. Oral Surg Oral Med Oral Pathol Oral Radiol Endod. 2000; 89(5):5706.

51. Lorini R, Scaramuzza A, Vitali $L$, et al. Clinical aspects of celiac disease in children with insulin-dependent diabetes mellitus. J Pediatr Endocrinol Metab 1996; 9(supplement 1):101-11.

52. Levin JA, Muzyka BC, Glick M. Dental management of patients with diabetes mellitus. Compend Contin Educ Dent. 1996; 17(1):82, 84, 86 passim.

53. Bell GW, Large DM, Barclay SC. Oral health care in diabetes mellitus. 2000; 55(3):158-65; quiz 175.Oliver RC, Tervonen T. Diabetes--a risk factor for periodontitis in adults? J Periodontol. 1994; 65(5 Suppl):530-8.

54. Lalla E, Cheng B, Lal S, Tucker S, Greenberg E, Goland R, Lamster IB. Periodontal changes in children and adolescents with diabetes: a case-control study. Diabetes Care. 2006; 29(2):295-9.

55. Moore PA, Guggenheimer J, Etzel KR, Weyant RJ, Orchard T. Type 1 diabetes mellitus, xerostomia, and salivary flow rates. Oral Surg Oral Med Oral 
Pathol Oral Radiol Endod. 2001; 92(3):281-91.

56. Grushka M, Epstein J, Mott A. An open-label, dose escalation pilot study of the effect of clonazepam in burning mouth syndrome.Oral Surg Oral Med Oral Pathol Oral Radiol Endod 1998; 86:557-61.

57. Abdulwassie H, Dhanrajani PJ. Diabetes mellitus and dental implants: a clinical study. Implant Dent. 2002; 11(1):83-6.

58. Morris HF, Ochi S, Winkler S. Implant survival in patients with type 2 diabetes: placement to 36 months. Ann Periodontol. 2000; 5(1):157-65.

59. Balshi TJ, Wolfinger GJ. Dental implants in the diabetic patient: a retrospective study. Implant Dent. 1999; 8(4):355-9.

60. Peled M, Ardekian L, TaggerGreen N, Gutmacher Z, Machtei
EE. Dental implants in patients with type 2 diabetes mellitus: a clinical study. Implant Dent. 2003; 12(2):116-22.

61. Farzad P, Andersson L, Nyberg J. Dental implant treatment in diabetic patients. Implant Dent. 2002; 11(3):262-7.

62. Fouad AF, Burleson J. The effect of diabetes mellitus on endodontic treatment outcome Data from an electronic patient record. J Am Dent Assoc. 2003; 134:43-51.

63. Taiwo JO. Oral health education needs of diabetic patients in Ibadan. Afr J Med Med Sci. 2000; 29(3-4):269-74.

64. Varon F, Mack-Shipman L. The role of the dental professional in diabetes care. J Contemp Dent Pract 2000; (1)2: 001-027. 